C2008 IEEE. Personal use of this material is permitted. However, permission to reprint/republish this material for advertising or promotional purposes or for creating new collective works for resale or redistribution to servers or lists, or to reuse any copyrighted component of this work in other works must be obtained from the IEEE. 


\title{
Derating of Asymmetric Three-Phase Transformers Serving Unbalanced Nonlinear Loads
}

\author{
Mohammad A. S. Masoum, Senior Member, IEEE, Paul S. Moses, and Amir S. Masoum, Student Member, IEEE
}

\begin{abstract}
A new analysis into the steady-state operation and derating of three-phase transformers under nonsinusoidal and asymmetric operating conditions is proposed. The combined effects of transformer core and load asymmetry, nonlinearity, and harmonics, as well as nonsinusoidal input excitation are examined. A time-domain nonlinear model for three-phase three-leg transformers is implemented. Transformer derating is estimated by modeling additional power losses due to harmonics generated by the iron core, nonsinusoidal excitation, and nonlinear (rectifier and electric drive) loading. Laboratory tests are performed to verify simulated waveforms. The contribution of this paper is a nonlinear transformer modeling technique for steady-state operation under unbalanced, asymmetric, and nonsinusoidal operation, capable of computing derating factors.
\end{abstract}

Index Terms-Asymmetry, derating, electric drives, harmonics, nonlinear loads, transformer losses.

\section{INTRODUCTION}

$\mathbf{P}$ ROPAGATION and generation of voltage and current harmonics in three-phase transformers has received considerable attention in literature. Much is known about transformer additional losses being symptomatic of nonsinusoidal operation, leading to thermal damage in the insulation, iron core, and windings [1]-[7]. However, past analyses have been mainly limited to balanced and symmetric operation of transformers.

The majority of transformer harmonic models assume symmetrical conditions. This is seldom true as transformers often operate in the presence of power system and load imbalances with asymmetry in the iron core. The complete extent of symptoms from unbalanced, asymmetric behavior, and nonsinusoidal operation is not so apparent in literature and limited documents have investigated such nonlinearities [8]-[14].

A significant step forward was the development of the nonlinear three-phase magnetic circuit model by Fuchs et al. [9], [10] that was later modified by Pedra et al. [15] to include asymmetric nonlinear core reluctances. Clua et al. [8] investigated unbalanced harmonic power flow in three-phase transformers by using admittance matrices and sequence component equivalent models. However, this model neglects core nonlinearity and

Manuscript received July 6, 2007; revised December 4, 2007. First published May 16, 2008; current version published September 24, 2008. Paper no. TPWRD-00419-2007.

M. A. S. Masoum and P. S. Moses are with the Department of Electrical and Computer Engineering, Curtin University of Technology, Perth, WA 6845, Australia (e-mail:m.masoum@curtin.edu.au).

A. S. Masoum is with the University of Western Australia, Crawley, WA 6009, Australia.

Digital Object Identifier 10.1109/TPWRD.2008.923057 assumes symmetrical core limbs with no harmonic interaction between the network and nonlinear loads.

The impact of unsymmetrical voltage sags on three-phase transformers has been studied by Pedra et al. [14]. The transformer model is similar to the one implemented in this paper. Previous work by Medina et al. [12], [13] derived a Norton harmonic representation of three-phase transformers. This frequency domain technique pioneered modeling asymmetrical core magnetization, harmonic cross coupling in the limbs, and harmonic power flow.

A simple and effective approach for the safe operation of transformers is to derate them under nonsinusoidal operating conditions. Derating is the intentional reduction in load capacity of a transformer under nonsinusoidal operation [16], [17]. It becomes necessary because nonsinusoidal operation gives rise to additional fundamental and harmonic losses which may produce excessive heating. Four general techniques are used to estimate the derating of transformers; K-Factor, harmonic loss factor $\left(F_{H L}\right)$ [2], [3], [16], [17], measured harmonic losses [1], [19], and computed harmonics losses [5]. The last approach will be used in this paper. Under nonsinusoidal operating conditions, the derated fundamental load current is computed such that total losses are equal to rated transformer losses. A similar method has been previously demonstrated by Masoum et al. [5].

In this paper, a nonlinear transformer model [15] is modified to include nonsinusoidal excitation, (non)linear and asymmetric loads, transformer core nonlinearity, core asymmetry and harmonic cross coupling effects in the legs. The developed transformer model is used to determine the additional losses and estimate the load reduction (e.g., transformer derating [5]) required to maintain safe operation under nonsinusoidal operation. Laboratory tests with linear and nonlinear transformer loading are performed to verify simulated waveforms and demonstrate the accuracy of the proposed model.

\section{NONLINEAR TRANSFORMER MODEL}

The proposed transformer model for asymmetrical, unbalanced and (non)sinusoidal operation is derived from reference [15]. It is based on the simultaneous solution of electric and magnetic equivalent circuits of three-phase three-leg transformers. The nodal equations of the circuits are solved in time domain using iterative techniques such as Newton-Raphson. The electric circuit governs the electrical connections of the source, load and the transformer. For three-phase transformers, the magnetic circuit is necessary to represent the multiple flux paths, reluctances and magnetomotive forces within multilegged iron core structures [18]. It also incorporates the asymmetric magnetizing behavior of the core. 


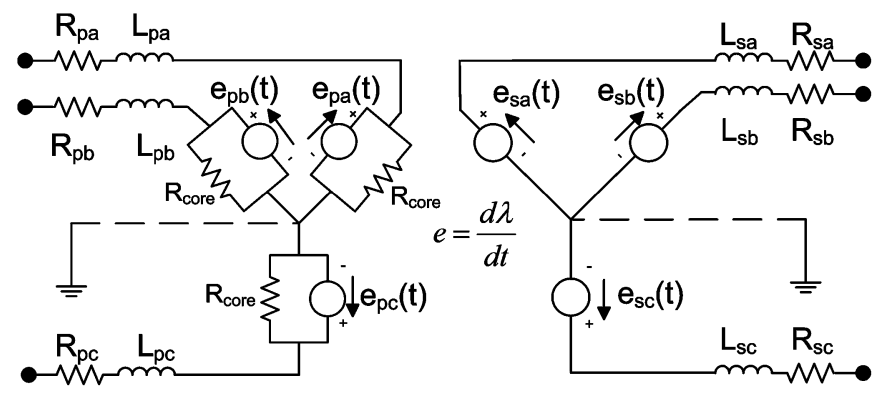

Fig. 1. Electric equivalent circuit of three-phase three-leg transformers.

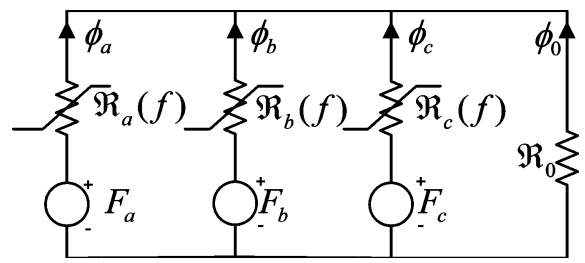

Fig. 2. Magnetic equivalent circuit of three-phase three-leg transformers.

\section{A. Electric Equivalent Circuit}

The electric circuit of Fig. 1 can be simulated by most software packages such as PSIM or PSPICE. Typically a nodal matrix of equations describing the circuit is formed and solved through iterative time-domain numerical techniques.

The induced primary and secondary voltages are modeled as voltage sources controlled by the time derivative of the magnetic fluxes (Faraday's Law). This establishes a link between the magnetic and electric circuits.

The transformer model implements core loss resistance $R_{\text {core }}$ as a linear element in parallel with the induced primary voltage. Some models use nonlinear resistances to represent core losses because they are functions of harmonic voltage magnitudes and phase angles [6], [11]. However, according to [15] a linear $R_{\text {core }}$ is a valid simplification with good agreement shown between model simulations and measured hysteresis loop areas, which are proportional to core losses. Likewise, winding resistances and leakage fluxes are assumed constant. Fuchs et al. [7] state this to be a valid approximation because the effects of saturation is usually negligible in winding elements.

In this paper, the electric circuit parameters, winding resistances, core loss resistances and leakage inductances are estimated from three-phase open circuit and short circuit tests.

\section{B. Magnetic Equivalent Circuit}

The circuit in Fig. 2 is an approximation of the equivalent circuit proposed by [9]. In this model, the seven reluctances of the core are reduced to three reluctance parameters which can be easily measured. This magnetic circuit can be programmed in PSPICE as an electrical circuit using the magnetic-electric duality principle.

The nonlinear reluctances in Fig. 2 are implemented in PSPICE as flux sources dependent on their own MMF drops

$$
\Phi\{f\}=f \Re\{f\}^{-1} .
$$

$F_{a}, F_{b}$, and $F_{c}$ are the MMFs developed in the limbs by electric circuit currents in the primary and secondary windings. This is another relationship linking the electric and magnetic circuits.

Nonlinear reluctance functions can be fitted to each leg's magnetizing characteristic [15]

$$
\Re\{f\}^{-1}=\frac{K_{1}}{\left[1+\left(\frac{|f|}{f_{0}}\right)^{1 / p}\right]}+K_{2}
$$

where the empirically determined parameters $K_{1}, K_{2}, p$, and $f_{0}$ are constants that shape the function to any measured saturation curve $(\Phi-f) . K_{1}$ and $K_{2}$ are associated with the slope of the linear and nonlinear regions, respectively, $p$ influences the smoothness of the knee region and $f_{0}$ defines where saturation starts.

The measurement procedure to obtain the magnetic circuit parameters of an asymmetric three-leg transformer is described in [9]. The zero-sequence open circuit test determines the linear air path reluctance, $\Re_{0}$. The $\lambda-i$ hysteresis loops for each limb can be obtained by exciting a phase at a time and integrating the corresponding induced voltages.

\section{TRANSFORMER DERATING}

\section{A. Modeling Additional Losses and Derating Factors}

The nonlinear transformer model (Figs. 1-2) is used to calculate the derating required for nonsinusoidal operating conditions. The backwards solution approach similar to [5] is adopted through the following steps.

Step 1: Compute rated losses by simulating the transformer for rated sinusoidal excitation with rated resistive load. PSPICE is used to sum the fundamental and harmonic losses using the following formula for each phase:

$$
\begin{aligned}
P_{\text {loss }} & =P_{\text {windings }}+P_{\text {core }} \\
& =I_{\text {windings-rms }}^{2} R_{\text {windings }}+I_{\text {core-rms }}^{2} R_{\text {core }}
\end{aligned}
$$

where

$$
I_{r m s}=\sqrt{\left(I_{r m s}^{h=1}\right)^{2}+\left(I_{r m s}^{h=2}\right)^{2}+\cdots+\left(I_{r m s}^{h=h \max }\right)^{2}} .
$$

Step 2: Impose nonsinusoidal operation (e.g., nonlinear loads and/or input voltage harmonics) while maintaining rated fundamental output kVA by ensuring that fundamental load current and fundamental output voltage are at rated values

$$
I_{S}^{1}=V_{S}^{1}=1 \mathrm{pu}
$$

Step 3: If the fundamental output voltage is not at its rated value due to reactive power demand, adjust the fundamental input voltage to compensate.

Step 4: Recalculate total power losses under nonsinusoidal conditions (Step 1) to determine the additional losses

$$
\Delta \text { Losses } \%=\frac{P_{\text {loss }, \text { new }}-P_{\text {loss }, \text { rated }}}{P_{\text {loss }, \text { rated }}} \times 100 \text {. }
$$


TABLE I

SiMULATION RESULTS FOR THE 60 KVA TRANSFORMER (FULL LOAD CONDITION)

\begin{tabular}{|c|c|c|c|c|c|c|c|c|c|c|c|c|c|c|}
\hline \multirow{3}{*}{ Case } & \multicolumn{3}{|c|}{ System and Load Conditions } & \multirow{2}{*}{\multicolumn{5}{|c|}{$\begin{array}{c}\text { Transformer Secondary Current [\%] } \\
\text { Harmonic Order }\end{array}$}} & \multirow{2}{*}{\multicolumn{5}{|c|}{$\begin{array}{c}\text { Transformer Secondary Voltage [\%] } \\
\text { Harmonic Order }\end{array}$}} & \multirow[b]{3}{*}{ Fig. } \\
\hline & \multirow{2}{*}{$\begin{array}{l}\text { Input } \\
\text { Voltage }\end{array}$} & \multirow{2}{*}{$\begin{array}{l}\text { Load } \\
\text { Type }\end{array}$} & \multirow{2}{*}{$\begin{array}{l}\text { Load } \\
\text { PF }\end{array}$} & & & & & & & & & & & \\
\hline & & & & $\mathrm{h}=1$ & $\mathrm{~h}=3$ & $\mathrm{~h}=5$ & $\mathrm{~h}=7$ & $\mathrm{THD}_{\mathrm{I}}$ & $\mathrm{h}=1$ & $\mathrm{~h}=3$ & $\mathrm{~h}=5$ & $\mathrm{~h}=7$ & $\mathrm{THD}_{\mathrm{V}}$ & \\
\hline 1 & \multirow{5}{*}{ Rated sinusoidal } & $\mathrm{R}$ & 1 & 99.4 & 0.09 & 0.03 & 0.01 & 0.10 & 99.4 & 0.09 & 0.03 & 0.01 & 0.10 & --- \\
\hline 2 & & $\mathrm{RL}$ & $0.8 \mathrm{lag}$ & 100.0 & 0.05 & 0.01 & 0.00 & 0.0 & 100 & 0.10 & 0.03 & 0.02 & 0.10 & 3 \\
\hline 3 & & $\mathrm{RC}$ & 0.8 lead & 100.1 & 0.21 & 0.23 & 0.13 & 0.34 & 100 & 0.11 & 0.07 & 0.03 & 0.13 & -- \\
\hline 4 & & $\begin{array}{c}\text { PWM } \\
\text { drive }\end{array}$ & --- & 104.0 & 0.07 & 40.6 & 13.6 & 41.3 & 99 & 0.64 & 7.50 & 4.11 & 8.70 & 4 \\
\hline 5 & & Rectifier & --- & 100.3 & 0.06 & 22.4 & 9.3 & 24.2 & 99.5 & 0.27 & 4.4 & 2.6 & 5.2 & --- \\
\hline 6 & \multirow{4}{*}{$\begin{array}{c}\text { Rated fundamental } \\
\text { and } 20 \% \\
5^{\text {th }} \text { harmonic }\end{array}$} & $\mathrm{R}$ & 1 & 99.4 & 0.13 & 19.2 & 0.08 & 19.3 & 99.4 & 0.13 & 19.2 & 0.08 & 19.3 & -- \\
\hline 7 & & $\mathrm{RL}$ & $0.8 \mathrm{lag}$ & 100.0 & 0.06 & 6.1 & 0.02 & 6.1 & 100 & 0.13 & 19.1 & 0.09 & 19.0 & 5 \\
\hline 8 & & $\mathrm{RC}$ & 0.8 lead & 100.1 & 0.29 & 140.1 & 0.79 & 139.9 & 100 & 0.18 & 44.8 & 0.13 & 44.7 & 6 \\
\hline 9 & & Rectifier & --- & 100.1 & 0.53 & 21.1 & 8.7 & 22.9 & 99 & 0.25 & 23.5 & 2.5 & 23.8 & 7 \\
\hline \multirow{3}{*}{${ }^{\dagger} 10$} & \multirow{3}{*}{$\begin{array}{l}\text { Asymmetry in } \\
\text { core and load }\end{array}$} & $\mathrm{R}$ & & 99.6 & 25.6 & 6.1 & 0.30 & 27.3 & 79.0 & 20.3 & 3.6 & 3.8 & 27.1 & $8(a)$ \\
\hline & & Rectifier & --- & 100.2 & 2.9 & 0.71 & 0.29 & 39.1 & 97.7 & 2.7 & 0.43 & 0.44 & 4.4 & $8(\mathrm{~b})$ \\
\hline & & $\mathrm{R}$ & & 100.7 & 3.0 & 0.62 & 0.61 & 3.2 & 97.3 & 2.9 & 0.60 & 0.59 & 3.2 & 8(c) \\
\hline
\end{tabular}

$\left.{ }^{\dagger}\right)$ The asymmetric case study simulates a transformer with a damaged phase A limb in the iron core while serving unbalanced linear and nonlinear loads. Asymmetric case waveforms contain even order harmonics which are not shown in the table.

TABLE II

COMPUTED DERATING FACTORS FOR THE 60 KVA TRANSFORMER

\begin{tabular}{|c|c|c|c|c|c|c|c|c|c|c|}
\hline \multirow[b]{2}{*}{ Case } & \multicolumn{2}{|c|}{ System and Load Conditions } & \multicolumn{4}{|c|}{ Transformer Losses } & \multirow[b]{2}{*}{$\begin{array}{c}\text { K- } \\
\text { Factor }\end{array}$} & \multirow[b]{2}{*}{$F_{H L}$} & \multicolumn{2}{|c|}{ Transformer Derating } \\
\hline & Input Voltage & $\begin{array}{l}\text { Load } \\
\text { Type }\end{array}$ & $\begin{array}{c}\text { Winding } \\
\text { Losses } \\
{[\mathrm{W}]}\end{array}$ & $\begin{array}{c}\text { Core } \\
\text { Losses } \\
{[\mathrm{W}]}\end{array}$ & $\begin{array}{c}\text { Total } \\
\text { Losses } \\
{[\mathrm{W}]}\end{array}$ & $\begin{array}{c}\Delta \text { Increase } \\
\text { in Losses } \\
{[\%]}\end{array}$ & & & $\begin{array}{c}\text { Derating } \\
\text { (model)* } \\
{[\%]}\end{array}$ & $\begin{array}{c}\text { Derating } \\
\left(K-F_{H L}\right)^{* *} \\
{[\%]}\end{array}$ \\
\hline 4 & Rated sinusoidal & PWM Drive & 230.1 & 520.1 & 750.2 & 7.5 & 6.10 & 4.87 & 10.4 & 11.8 \\
\hline 6 & Nonsinusoidal: & $\mathrm{R}$ & 187.0 & 537.1 & 724.1 & 3.8 & 1.92 & 1.87 & 8.0 & 3.2 \\
\hline 7 & rated fundamental & $\mathrm{RL}$ & 189.9 & 555.7 & 745.6 & 6.9 & 1.10 & 1.09 & 15.0 & 0.35 \\
\hline 8 & and $20 \%$ & $\mathrm{RC}$ & 527.4 & 563.1 & 1090.5 & 56.3 & 50.55 & 16.95 & 18.7 & 53.7 \\
\hline 9 & $5^{\text {th }}$ harmonic & Rectifier & 194.2 & 541.8 & 736 & 5.5 & 2.48 & 2.38 & 10.7 & 5.1 \\
\hline
\end{tabular}

‡) Rated losses of the $60 \mathrm{kVA}$ transformer is $697 \mathrm{~W}$.

*) Computed derating based on losses from the nonlinear transformer model (Figs. 1-2).

${ }^{* *}$ ) Computed derating using IEEE standard C57.110 (K-Factor and $F_{H L}$ ).

Step 5: Use PSPICE's optimization feature (performance tool) to decrease the load level until total losses equals rated losses. This is achieved by inserting an arbitrary resistance $R_{\text {derate }}$ in series with the load and adjusting its value until rated losses occurs:

$$
\left.P_{\text {loss }}\right|_{I_{s}^{1}=I_{\text {derated }}}=P_{\text {loss }, \text { rated }} .
$$

The result is the new current magnitude ( $I_{\text {derated }}$, expressed in per-unit) that the transformer can deliver without exceeding rated losses.

Step 6: The new (derated) apparent power can be computed as

$$
k V A_{\text {derated }}=k V A_{\text {rated }} \times I_{\text {derated }} .
$$

Therefore, the percentage decrease in $\mathrm{kVA}$ rating is

$$
\text { Derating }=\left(1-I_{\text {derated }}\right) \times 100 \text {. }
$$

\section{B. K-Factor and Harmonic Loss Factor}

IEEE Standard C57.110 (1986) [16] is developed to limit transformer temperature rise due to nonsinusoidal load currents.
It describes a method to calculate the load reduction required to not exceed rated losses given the harmonic spectra of the load current. Underwriters Laboratories derived the K-Factor from this standard which is used to specify a class of transformers capable of serving nonsinusoidal loads. In 1998, C57.110 standard was updated with a factor similar to the K-Factor called the harmonic loss factor $\left(F_{H L}\right)[17]$

$$
\begin{aligned}
K & =\sum_{h=1}^{h \max } \frac{I_{h}^{2} h^{2}}{I_{R}^{2}} \\
F_{H L} & =\sum_{h=1}^{h \max } \frac{I_{h}^{2} h^{2}}{I_{h}^{2}}
\end{aligned}
$$

which are related as follows:

$$
K=\frac{\sum_{h=1}^{h \max } I_{h}^{2}}{I_{R}^{2}} F_{H L}
$$

where $I_{h}$ is the rms load current at harmonic order $h$, and $I_{R}$ represents the rated rms load current of the transformer. 
TABLE III

SimUlation RESUlts FOR THE 1 KVA TRANSFORMER (FULl LOAD CONDITION)

\begin{tabular}{|c|c|c|c|c|c|c|c|c|c|c|c|c|c|c|}
\hline \multirow{3}{*}{ Case } & \multicolumn{3}{|c|}{ System and Load Conditions } & \multirow{2}{*}{\multicolumn{5}{|c|}{$\begin{array}{c}\text { Transformer Secondary Current [\%] } \\
\text { Harmonic Order }\end{array}$}} & \multirow{2}{*}{\multicolumn{5}{|c|}{$\begin{array}{c}\text { Transformer Secondary Voltage [\%] } \\
\text { Harmonic Order }\end{array}$}} & \multirow{3}{*}{ Fig } \\
\hline & \multirow{2}{*}{$\begin{array}{l}\text { Input } \\
\text { Voltage }\end{array}$} & \multirow{2}{*}{$\begin{array}{l}\text { Load } \\
\text { Type }\end{array}$} & \multirow{2}{*}{$\begin{array}{l}\text { Load } \\
\text { PF }\end{array}$} & & & & & & & & & & & \\
\hline & & & & $\mathrm{h}=1$ & $\mathrm{~h}=3$ & $\mathrm{~h}=5$ & $\mathrm{~h}=7$ & THD $_{I}$ & $\mathrm{~h}=1$ & $\mathrm{~h}=3$ & $\mathrm{~h}=5$ & $\mathrm{~h}=7$ & $\mathrm{THD}_{\mathrm{V}}$ & \\
\hline 1 & & $\mathbf{R}$ & 1 & 100.0 & 0.01 & 0.0 & 0.0 & 0.0 & 100.0 & 0.01 & 0.0 & 0.0 & 0.01 & 10 \\
\hline 2 & & $\mathrm{RL}$ & $0.8 \mathrm{lag}$ & 100.1 & 0.01 & 0.0 & 0.0 & 0.01 & 100.1 & 0.01 & 0.0 & 0.0 & 0.01 & --- \\
\hline 3 & Rated sinusoidal & $\mathrm{RC}$ & 0.8 lead & 100.4 & 0.02 & 0.0 & 0.0 & 0.02 & 100.4 & 0.01 & 0.0 & 0.0 & 0.01 & -- \\
\hline 4 & & $\begin{array}{l}\text { PWM } \\
\text { drive }\end{array}$ & -- & 100.1 & 0.20 & 46.7 & 16.0 & 49.3 & 100.1 & 0.17 & 4.67 & 1.55 & 4.92 & -- \\
\hline 5 & & Rectifier & --- & 100.5 & 0.23 & 22.3 & 10.7 & 24.6 & 99.9 & 0.03 & 2.18 & 1.10 & 2.44 & 11 \\
\hline 6 & & $\mathrm{R}$ & 1 & 100.0 & 0.03 & 19.8 & 0.02 & 19.8 & 100.0 & 0.03 & 19.8 & 0.02 & 19.8 & --- \\
\hline 7 & & RL & $0.8 \mathrm{lag}$ & 100.1 & 0.01 & 6.76 & 0.0 & 6.76 & 100.1 & 0.01 & 21.2 & 0.01 & 21.1 & -- \\
\hline 8 & and $20 \%$ & $\mathrm{RC}$ & 0.8 lead & 100.4 & 0.04 & 64.1 & 0.07 & 63.9 & 100.4 & 0.01 & 20.5 & 0.01 & 20.4 & --- \\
\hline 9 & "inarmonic & Rectifier & --- & 99.8 & 0.19 & 5.53 & 11.8 & 13.1 & 100.0 & 0.06 & 22.2 & 1.18 & 22.3 & --- \\
\hline
\end{tabular}

TABLE IV

COMPUTED DERATING FACTORS FOR THE $1 \mathrm{KVA}$ TRANSFORMER

\begin{tabular}{|c|c|c|c|c|c|c|c|c|c|c|}
\hline \multirow[b]{2}{*}{ Case } & \multicolumn{2}{|c|}{ System and Load Conditions } & \multicolumn{4}{|c|}{ Transformer Losses } & \multirow[b]{2}{*}{$\begin{array}{c}\mathrm{K}- \\
\text { Factor }\end{array}$} & \multirow[b]{2}{*}{$F_{H L}$} & \multicolumn{2}{|c|}{ Transformer Derating } \\
\hline & Input Voltage & $\begin{array}{l}\text { Load } \\
\text { Type }\end{array}$ & $\begin{array}{l}\text { Winding } \\
\text { Losses } \\
{[\mathrm{W}]}\end{array}$ & $\begin{array}{c}\text { Core } \\
\text { Losses } \\
{[\mathrm{W}]}\end{array}$ & $\begin{array}{c}\text { Total } \\
\text { Losses } \\
{[\mathrm{W}]}\end{array}$ & $\begin{array}{c}\Delta \text { Increase } \\
\text { in Losses } \\
{[\%]}\end{array}$ & & & $\begin{array}{c}\text { Derating } \\
\text { (model) } \\
{[\%]}\end{array}$ & $\begin{array}{c}\text { Derating } \\
\left(K-F_{H L}\right) \\
{[\%]}\end{array}$ \\
\hline 4 & Rated sinusoidal & PWM Drive & 112.8 & 18.6 & 131.4 & 20.0 & 7.72 & 6.19 & 12.2 & 10.5 \\
\hline 6 & Nonsinusoidal: & $\mathrm{R}$ & 94.5 & 19.3 & 113.8 & 3.9 & 1.98 & 1.90 & 2.3 & 2.08 \\
\hline 7 & rated fundamental & $\mathrm{RL}$ & 92.4 & 19.4 & 111.8 & 2.1 & 1.12 & 1.11 & 1.1 & 0.26 \\
\hline 8 & and $20 \%$ & $\mathrm{RC}$ & 126.2 & 19.2 & 145.4 & 32.7 & 11.28 & 7.95 & 11.8 & 13.3 \\
\hline 9 & $5^{\text {th }}$ harmonic & Rectifier & 92.1 & 19.5 & 111.6 & 1.9 & 1.76 & 1.73 & 1.4 & 1.70 \\
\hline
\end{tabular}

$\left.{ }^{\ddagger}\right)$ Rated losses of the $1 \mathrm{kVA}$ transformer is $110 \mathrm{~W}$.

The K-Factor or the harmonic loss factor can be used to calculate the derating of transformers [27] given the load current harmonics and the rated eddy current losses $\left(P_{E C-R}\right)$

$$
I_{\text {derated }}=\sqrt{\frac{1+P_{E C-R}}{1+K \underbrace{\frac{I_{R}^{2}}{h \sum_{h=1}^{\max } I_{h}^{2}}}_{=F_{H L}}\left(P_{E C-R}\right)}}(\mathrm{pu}) .
$$

\section{Simulation Results}

There are three sources of nonlinearity and harmonic generation in three-phase transformers; nonlinearity of the magnetic core (e.g., internally generated nonsinusoidal magnetizing current), nonlinear loading (e.g., harmonic currents in the output terminal), and nonsinusoidal excitation (e.g., input harmonic voltages). To investigate the impacts of these sources on the performance, losses and derating of transformers, three operating conditions are investigated; sinusoidal excitation with (non)linear loads, nonsinusoidal excitation with (non)linear loads, and asymmetrical operation (Tables I-IV). Simulations are performed for two three-phase, wye-G/wye-G connected, $50 \mathrm{~Hz}$ transformers: $60 \mathrm{kVA}, 380 / 220 \mathrm{~V}$ [15] and $1 \mathrm{kVA}, 440 / 50$ V.

\section{A. Cases 1-3: Sinusoidal Excitation With Linear Loads}

With rated sinusoidal input voltages, three types of wye-connected loads (R, series RL and parallel RC) are simulated (Table I). Therefore, the only sources of harmonics are the nonlinearities associated with the transformer magnetic core. Fig. 3 shows simulation results for sinusoidal excitation with a rated series RL load. As expected, the nonsinusoidal magnetizing current is small and has no significant impact on the input and output waveforms.

\section{B. Case 4: Sinusoidal Excitation With Three-Phase VSI-PWM-Based Induction Motor Drive}

Most harmonics in power transformers are due to nonlinear loads at the output terminals. To demonstrate this phenomenon, a voltage source inverter PWM drive system is used as a nonlinear load at the secondary terminals of the nonlinear threephase transformer. The PSPICE nonlinear transformer model (Section II) is combined with an ac-dc rectifier and dc-ac PWM inverter. The PSPICE model for PWM inverter circuits from [26] is slightly modified into a variable frequency VSI-PWMbased induction motor drive implemented with the nonlinear transformer model. The load is selected such that rated fundamental output kVA is delivered. Simulation results are shown in Fig. 4. The motor drive load exhibits significant 5 th and 7 th order current harmonics $\left(\mathrm{THD}_{I}=41.3 \%\right)$ and distorts the transformer secondary voltage $\left(\mathrm{THD}_{V}=8.7 \%\right)$ for the $60 \mathrm{kVA}$ transformer. 


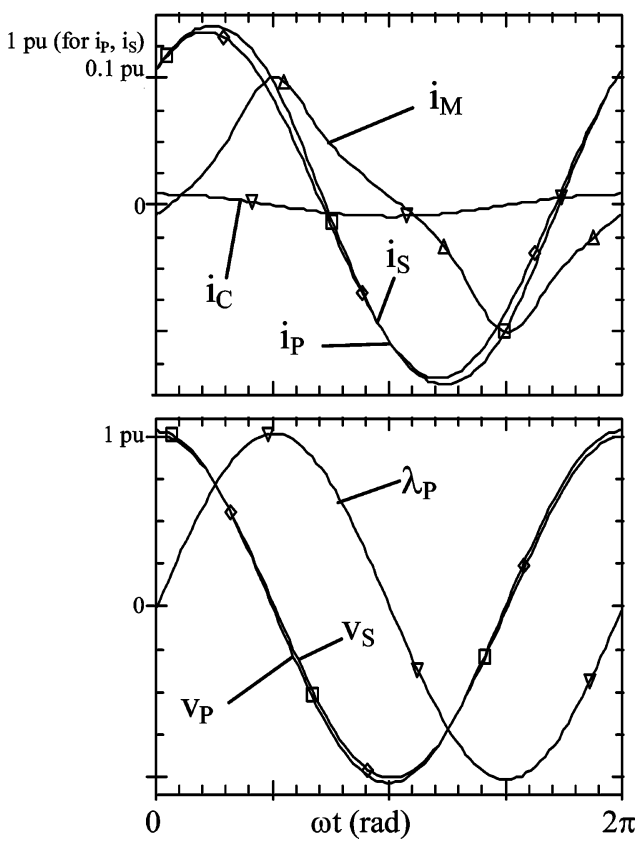

Fig. 3. Case 2-Transformer operation with rated sinusoidal excitation and rated $\mathrm{kVA}$ delivered to wye-connected series RL loads (power factor $=0.8$ lagging). Full load magnetizing $\left(i_{M}\right)$ and core loss $\left(i_{C}\right)$ currents, primary $\left(i_{P}\right)$ and secondary $\left(i_{S}\right)$ currents, primary flux linkages $\left(\lambda_{P}\right)$, primary $\left(V_{P}\right)$ and secondary $\left(V_{s}\right)$ voltages are shown in per-unit of rated values.

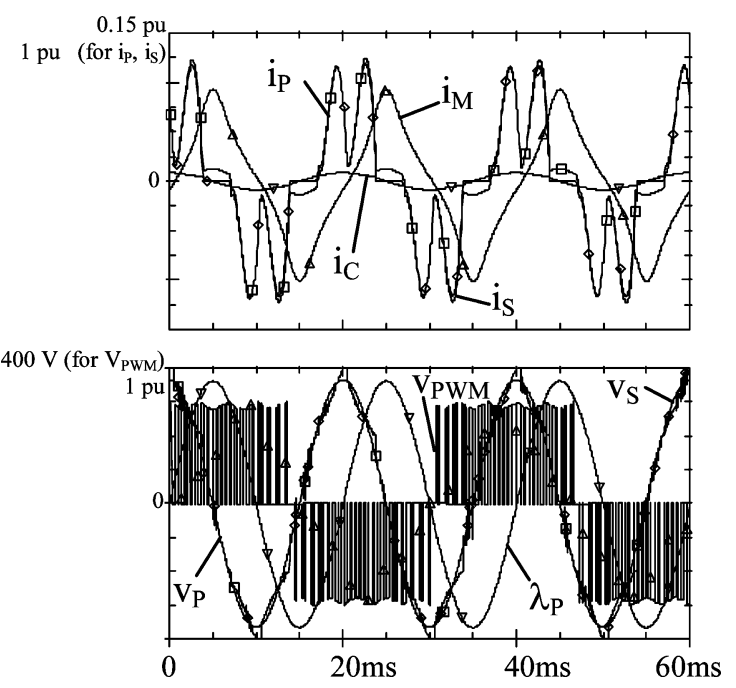

Fig. 4. Case 4-Transformer operation with rated sinusoidal excitation and three-phase VSI-PWM-based induction motor drive $\left(f_{P W M}=25 \mathrm{~Hz}\right)$.

\section{Case 5: Sinusoidal Excitation With Three-Phase Diode Bridge Rectifier Load}

A three-phase diode bridge rectifier (with rated resistive load on the dc side) is placed at the output terminals of the transformer. The load is adjusted such that rated fundamental output $\mathrm{kVA}$ is delivered. The nonlinear load deteriorates the power quality of the output current $\left(\mathrm{THD}_{i}=24.2 \%\right)$ and output voltage $\left(\mathrm{THD}_{v}=5.2 \%\right)$ in the $60 \mathrm{kVA}$ transformer.
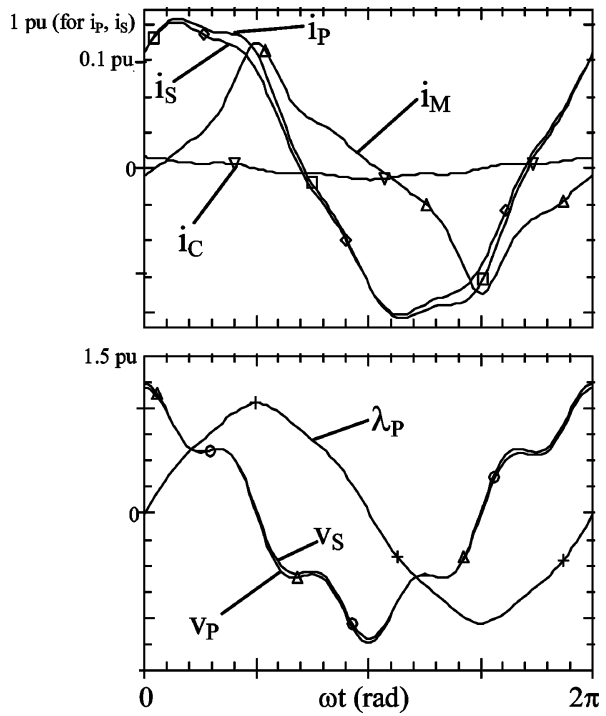

Fig. 5. Case 7-Transformer operation with nonsinusoidal excitation (20\% 5th harmonic) and rated fundamental $\mathrm{kVA}$ delivered to wye-connected series RL loads (power factor $=0.8$ lagging).

\section{Cases 6-8: Nonsinusoidal Excitation With Linear Loads}

The transformer is excited by nonsinusoidal voltages with rated fundamental component and different orders, magnitudes and phase angle of harmonic components. Simulations are performed for no-load, as well as R, RL, and RC loads. Fig. 5 shows input and output waveforms for the rated series RL load and rated fundamental input voltage excitation with $20 \%$ of 5 th harmonic at a phase shift of zero degree. Compared to Fig. 3, the magnetizing current $\left(i_{M}\right)$ and primary flux linkages $\left(\lambda_{P}\right)$ waveforms are more distorted and their total harmonic distortions have increased.

\section{E. Case 9: Nonsinusoidal Excitation With Three-Phase Diode Bridge Rectifier Load}

The transformer is connected to a three-phase diode bridge rectifier (with rated resistive load on the dc side) and is excited by nonsinusoidal voltages with rated fundamental component and $20 \%$ of 5 th harmonic at a phase shift of zero degree. Simulation results are shown in Fig. 7.

\section{F. Case 10: Operation With Core and Load Asymmetries}

Transformer input and output waveforms are computed under asymmetric three-phase loading condition and asymmetric iron core structure. Rated resistive loads are placed on phases A and $\mathrm{C}$ and a single-phase half-wave diode rectifier (with rated resistive load on the dc side) is connected to phase B. Phase A leg is assumed to be damaged. A damaged leg refers to a leg's magnetizing characteristic that has been significantly changed (e.g., 50\% reduction) such that excitations with well below rated voltage causes operation in the nonlinear region for that leg. Simulation results (Fig. 8) show that the secondary voltage for phase A is severely distorted. Furthermore, the damaged leg causes small voltage distortions in the "healthy" legs (phases 


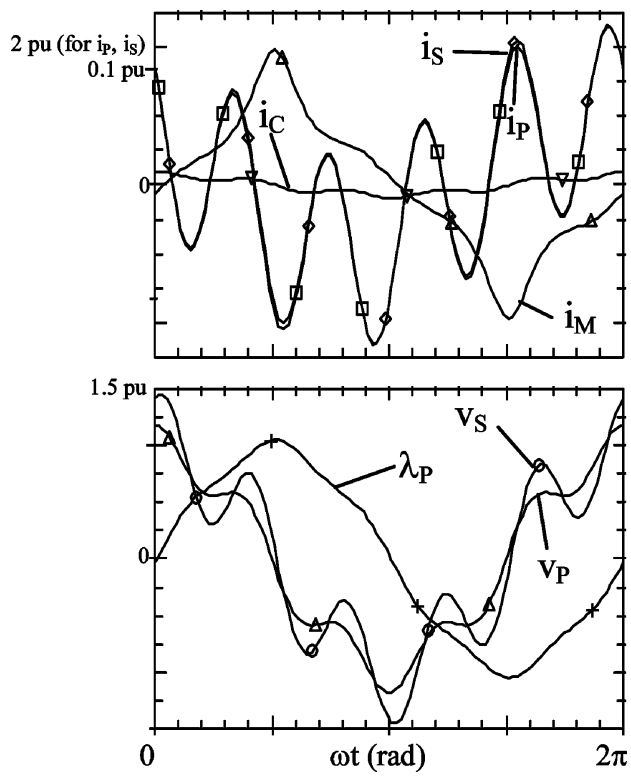

Fig. 6. Case 8-Transformer operation with nonsinusoidal excitation (20\% 5th harmonic) and rated fundamental kVA delivered to wye-connected parallel RC loads (power factor $=0.8$ leading) .

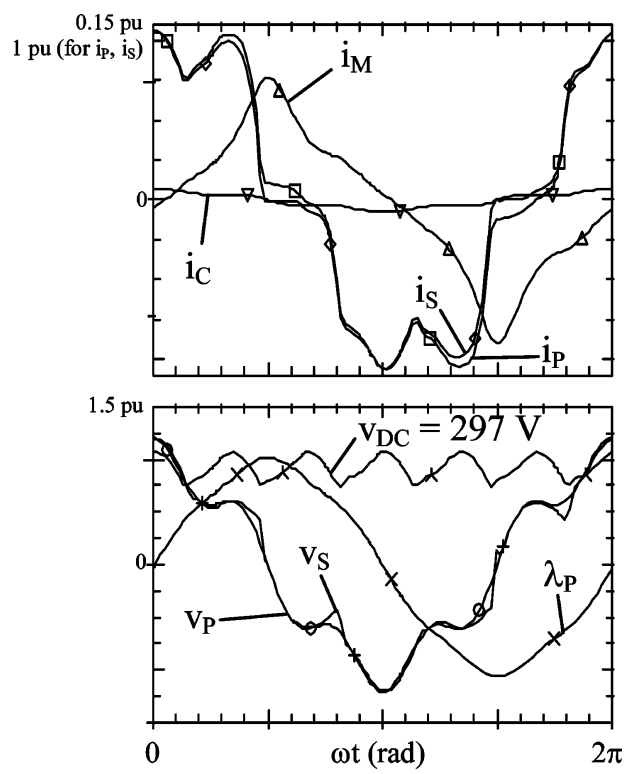

Fig. 7. Case 9-Transformer operation with nonsinusoidal excitation (20\% 5th harmonic) and rated fundamental kVA delivered to a three-phase diode bridge rectifier with resistive dc load.

B and C). The magnetizing waveforms are affected by the damaged leg, compared to the nominal symmetrical case. This is due to flux interaction with the other limbs.

\section{G. Additional Losses and Derating of Transformer}

The nonlinear transformer model is used to calculate the derating required for five of the above mentioned case studies. For comparison, the derating based on C57.110 ( $F_{H L}$ and K-Factor) for each case study has also been calculated (Tables II and IV). The calculations are performed with the assumption that eddy current losses comprise $5 \%$ of total losses.
The influence of load, power factor, nonlinearity, and input harmonic voltages on derating is demonstrated in Fig. 9. The fundamental kVA delivered to the load is maintained at rated operation while the fifth harmonic magnitude with zero degree phase shift was increased from 0 to $20 \%$ of fundamental magnitude. The total losses rise at a different rate for each type of load. The parallel RC load is highly sensitive to input harmonic voltage magnitudes (due to the occurrence of a resonance condition, Fig. 6). This demonstrates transformers feeding capacitive loads may require significant derating when exposed to voltage harmonics. The three-phase rectifier, PWM motor drive load and RL series load show transformer losses always above rated operation regardless of the presence of input harmonic voltages.

Tables II and IV show the derating factors required for some of the case studies. As expected, cases with input voltage harmonics and nonlinear loads require the most derating (e.g., $18.7 \% \mathrm{kVA}$ reduction for the $60 \mathrm{kVA}$ transformer with nonsinusoidal excitation and rated RC loading).

For the $1 \mathrm{kVA}$ transformer, there is good agreement between derating factors computed based on C57.110 and the proposed model (Table IV). However, the results for the $60 \mathrm{kVA}$ transformer derating show some disagreement. Several reasons exist for this discrepancy. Pierce [4] states "There is no allowance in C57.110 for any increase in core loss for nonsinusoidal currents" whereas the proposed model does include harmonic core losses. Thus, as core losses become insignificant (e.g., for the small $1 \mathrm{kVA}$ transformer), the error between derating factors based on the model and C57.110 decreases.

Another source of error is the rated eddy losses $\left(P_{E C-R}\right)$ estimation. By inspection of (11), large K-Factor and $F_{H L}$ will magnify any errors in $P_{E C-R}$. Furthermore, the K-Factor and $F_{H L}$ methods do not account for the dependence of eddy current losses on harmonic voltages and their phase shifts, and in fact, assume the primary voltage to be sinusoidal. It is also stated in [16], [17] that C57.110 applies to two winding transformers, however, asymmetric core effects are not included.

\section{VALIDATION OF RESUlts}

To investigate the accuracy of the proposed nonlinear model, laboratory measurements were performed for a three-phase, three-leg, $1 \mathrm{kVA}, 440 / 55 \mathrm{~V}, 50 \mathrm{~Hz}$ transformer. A Fluke 434 power quality analyzer was used to capture steady-state waveforms and harmonic spectra. The two scenarios investigated are rated wye-connected resistive load and three-phase rectifier with rated dc load (Figs. 10 and 11). The transformer was excited with rated three-phase voltages containing small amounts of low order harmonics.

\section{A. Rated Linear Load}

Balanced three-phase wye-connected resistive loads were connected to the transformer secondary. Simulated and measured waveforms for the rated linear load show excellent agreement (Fig. 10). This confirms the validity of the model to predict steady-state responses for linear load conditions.

\section{B. Three-Phase Diode Bridge Rectifier With Rated DC Load}

Waveforms for a nonlinear load were simulated and measured through the use of a three-phase diode bridge rectifier with a dc 

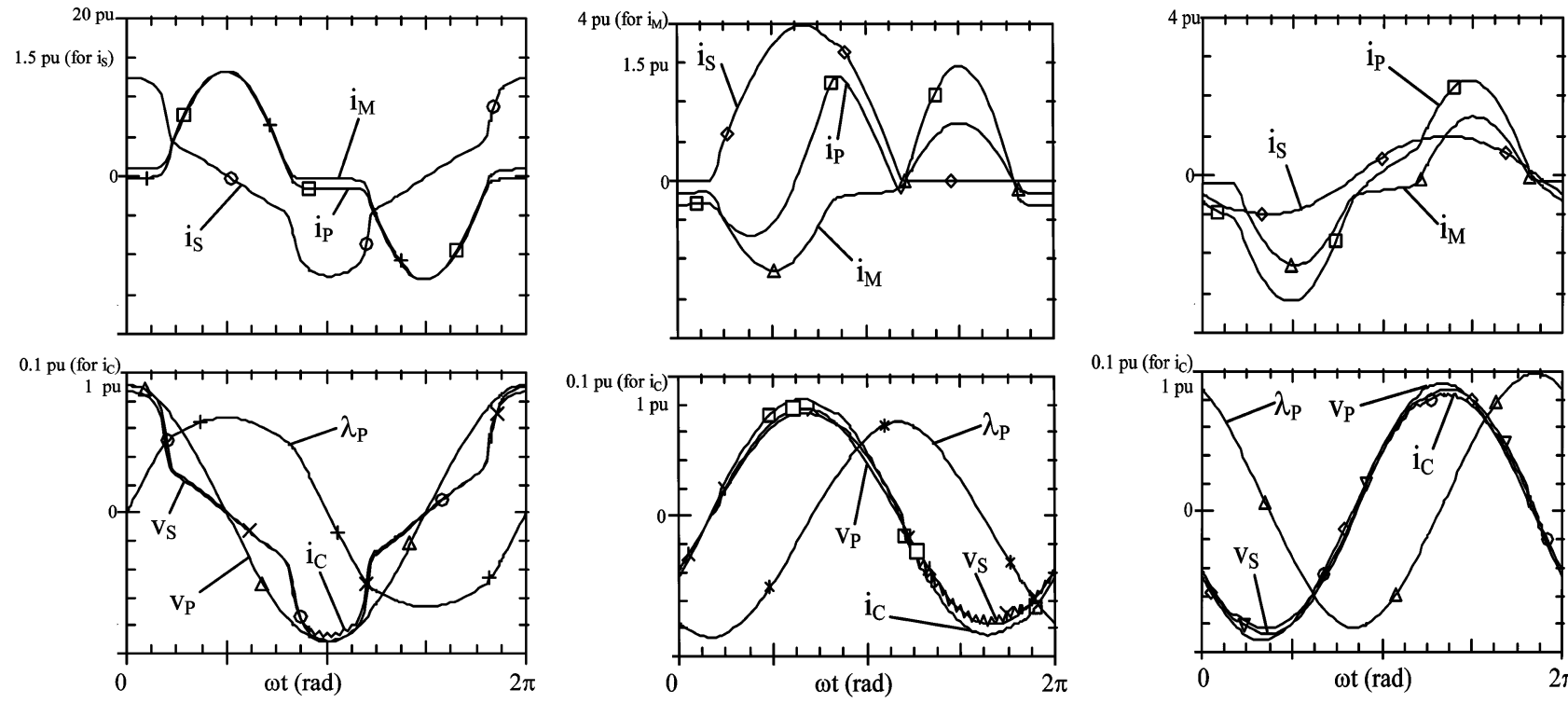

(a)

(b)

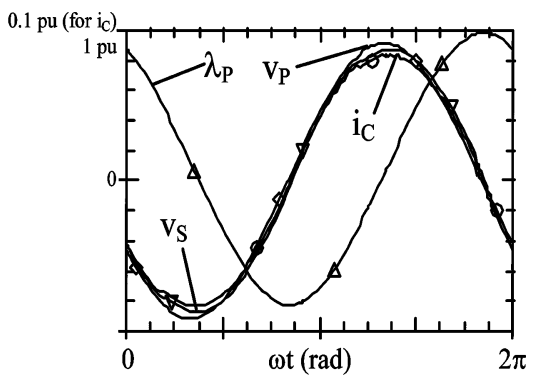

(c)

Fig. 8. Case 10-Transformer operation with asymmetric load (phase A: resistive load, phase B: half-wave diode rectifier load and phase C: resistive load) and asymmetric iron core (damaged core for phase $\mathrm{A}$ ). Full load magnetizing $\left(i_{M}\right)$ and core loss $\left(i_{C}\right)$ currents, primary $\left(i_{P}\right)$ and secondary $\left(i_{S}\right)$ currents, primary flux linkages $\left(\lambda_{P}\right)$, primary $\left(V_{P}\right)$ and secondary $\left(V_{s}\right)$ voltages are shown in per-unit of rated values for (a) phase A, (b) phase B, and (c) phase C.

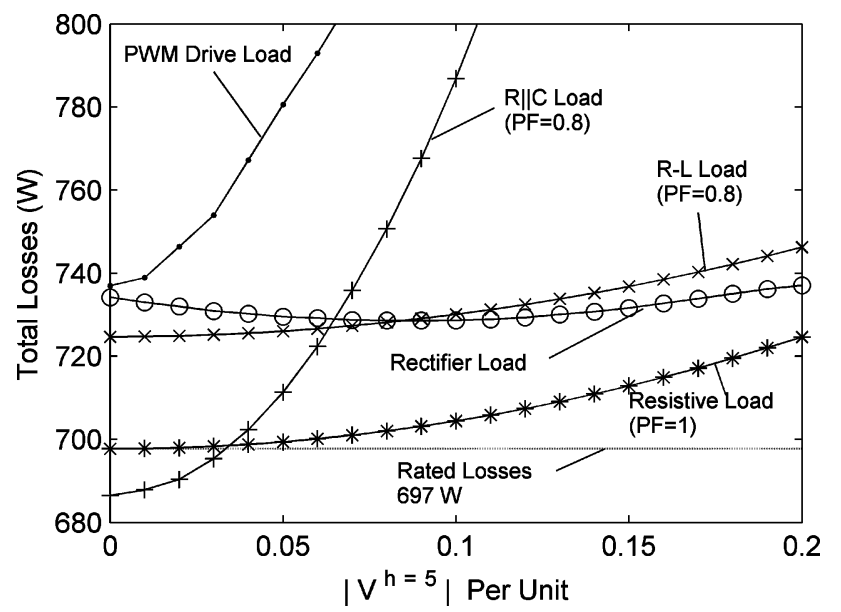

Fig. 9. Impact of 5th harmonic excitation voltage on the $60 \mathrm{kVA}$ transformer losses (harmonic magnitude: 0 to 0.2 pu and harmonic phase angle: zero degree).

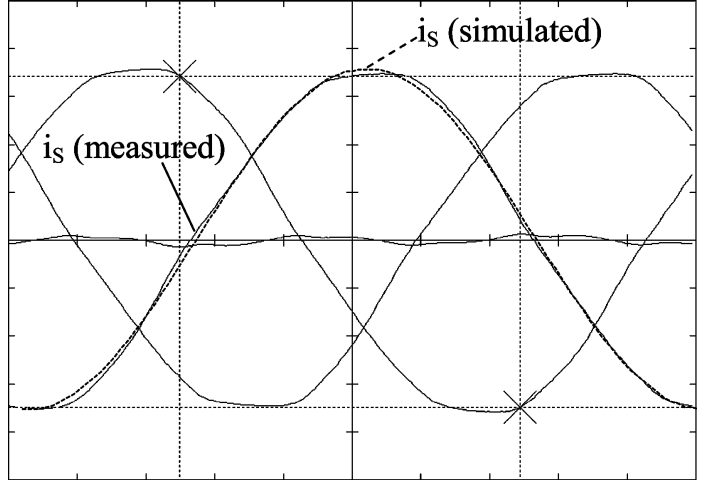

Fig. 10. Simulated and measured secondary current waveforms for the $1 \mathrm{kVA}$ transformer serving a linear load consisting of wye-connected resistors operating at rated apparent power.

side resistor. The load was adjusted so that rated fundamental apparent power was delivered from the transformer to the

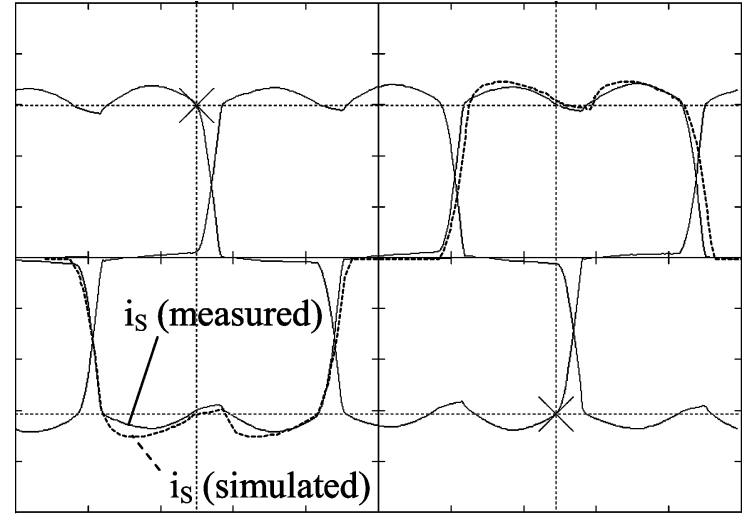

(a)

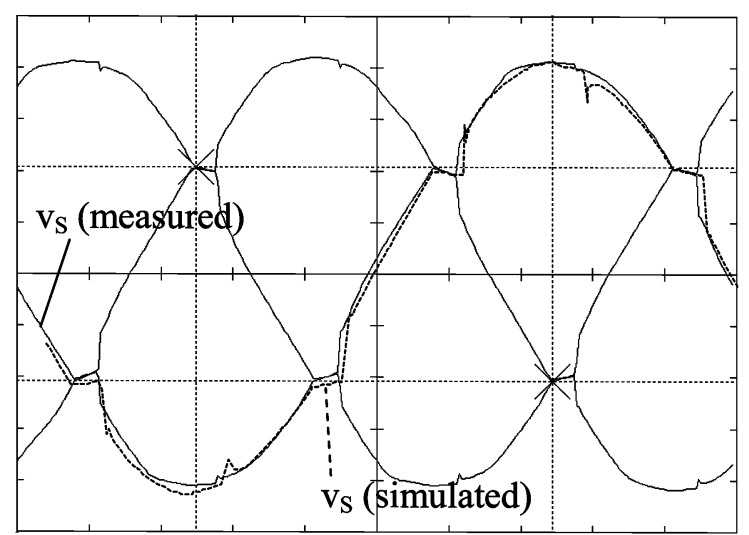

(b)

Fig. 11. Simulation and measured waveforms for the $1 \mathrm{kVA}$ transformer serving a three-phase rectifier load: (a) secondary currents and (b) secondary voltages.

rectifier dc load. Laboratory and model simulations agree with good accuracy (Fig. 11). 


\section{CONCLUSIONS}

A nonlinear transformer model has been adapted to compute input and output voltage and current waveforms, as well as, total losses and derating under linear and nonlinear load conditions. Nonsinusoidal excitation, asymmetry of the magnetic core and nonlinearity of the loads are included and demonstrated in the analysis. The accuracy of the model is verified by comparing the simulated and measured waveforms for rated resistive and nonlinear three-phase rectifier loads. The following observations are made:

- nonsinusoidal excitation and/or nonlinear loading deteriorate the power quality of input and output voltages and currents, causing significant increases in losses that require large derating of the transformer;

- asymmetry of the load has influence on transformer magnetizing current waveforms; however, it does not cause considerable output voltage distortion;

- asymmetric iron core saturation (due to damaged leg) severely distorts the voltage of the asymmetric phase; furthermore, the damaged leg causes small voltage distortions in the "healthy" legs;

- derating values based on K-Factor/ $F_{H L}$ and the proposed model agree well when transformer core losses are small; thus, for large transformers there is a potential improvement using the proposed derating method which, unlike the IEEE C57.110 standard, includes the effect of fundamental and harmonic core losses, nonsinusoidal input voltages, and asymmetric nonlinear cores;

- transformer operation with a wye-connected RC parallel load was shown to have adverse effects when 5th harmonic voltages were imposed at the input terminals; this is due to the occurrence of resonance causing the transformer to exhibit excessive power losses and require large derating;

- several limitations might be encountered in this model; complex circuits may cause difficulties in PSPICE's Newton-Raphson algorithm to converge to a solution; furthermore, accurate model parameters might be difficult to determine from measurements and can potentially introduce large errors into simulations;

- the presented simulation technique is general and can be applied to most three-phase distribution transformers with three-leg cores; the transformer model could be included in large power system simulations for power quality assessment and derating considerations.

\section{REFERENCES}

[1] E. F. Fuchs, D. Lin, and J. Martynaitis, "Measurement of three-phase transformer derating and reactive power demand under nonlinear loading conditions," IEEE Trans. Power Del., vol. 21, no. 2, pp. 665-672, Apr. 2006.

[2] D. Yildirim and E. F. Fuchs, "Measured transformer derating and comparison with harmonic loss factor approach," IEEE Tran. Power Del., vol. 15, pp. 186-191, Jan. 2000.

[3] E. F. Fuchs, D. Yildirim, and W. M. Grady, "Measurement of eddycurrent loss coefficient PEC-R, derating of single-phase transformers, and comparison with K-factor approach," IEEE Trans. Power Del., vol. 15 , no. 1, pp. 148-154, Jan. 2000.

[4] L. W. Pierce, "Transformer design and application considerations for nonsinusoidal load currents," IEEE Trans. Ind. Appl., vol. 32, no. 3, pp. 633-645, May/Jun. 1996.
[5] M. A. S. Masoum, E. F. Fuchs, and D. J. Roesler, "Impact of nonlinear loads on anisotropic transformers," IEEE Trans. Power Del., vol. 6, no. 4, pp. 1781-1788, Oct. 1991.

[6] M. A. S. Masoum, E. F. Fuchs, and D. J. Roesler, "Large signal nonlinear model of anisotropic transformers for nonsinusoidal operation. II. Magnetizing and core-loss currents," IEEE Trans. Power Del., vol. 6, no. 1, pp. 1509-1516, Jan. 1991.

[7] E. F. Fuchs, M. A. S. Masoum, and D. J. Roesler, "Large signal nonlinear model of anisotropic transformers for nonsinusoidal operation. I. Lambda-I characteristics," IEEE Trans. Power Del., vol. 6, pt. 1, pp. 1874-1886, Jan. 1991.

[8] J. Clua, L. Sainz, and F. Corcoles, "Three-phase transformer modeling for unbalanced harmonic power flow studies," in Proc. 9th Int. Conf. Harmonics and Quality of Power, 2000, pp. 726-731.

[9] E. F. Fuchs and Y. Yiming, "Measurement of lambda-I characteristics of asymmetric three-phase transformers and their applications," IEEE Trans. Power Del., vol. 17, no. 4, pp. 983-990, Oct. 2002.

[10] E. F. Fuchs, Y. You, and D. J. Roesler, "Modeling and simulation, and their validation of three-phase transformers with three legs under dc bias," IEEE Trans. Power Del., vol. 14, no. 2, pp. 443-449, Apr. 1999.

[11] M. A. S. Masoum and E. F. Fuchs, "Transformer magnetizing current and iron-core losses in harmonic power flow," IEEE Trans. Power Del., vol. 9, no. 1, pp. 10-20, Jan. 1994.

[12] A. Medina and J. Arrillaga, "Generalized modelling of power transformers in the harmonic domain," IEEE Trans. Power Del., vol. 7, no. 3, pp. 1458-1465, Jul. 1992.

[13] A. Medina and J. Arrillaga, "Simulation of multilimb power transformers in the harmonic domain," Proc. Inst. Elect. Eng., vol. 139, pp. 269-276, 1992.

[14] J. Pedra, L. Sainz, F. Corcoles, and L. Guasch, "Symmetrical and unsymmetrical voltage sag effects on three-phase transformers," IEEE Trans. Power Del., vol. 20, no. 2, pt. 2, pp. 1683-1691, Apr. 2005.

[15] J. Pedra, L. Sainz, F. Corcoles, R. Lopez, and M. Salichs, "PSPICE computer model of a nonlinear three-phase three-legged transformer," IEEE Trans. Power Del., vol. 19, no. 1, pp. 200-207, Jan. 2004.

[16] IEEE Recommended Practice for Establishing Transformer Capability When Supplying Nonsinusoidal Load Currents, ANSI/IEEE Std. C57. 110-1986, 1988.

[17] IEEE Recommended Practice for Establishing Transformer Capability When Supplying Nonsinusoidal Load Currents, IEEE Std. C57.1101998, 1998.

[18] G. Chang, C. Hatziadoniu, W. Xu, P. Ribeiro, R. Burch, W. M. Grady, M. Halpin, Y. Liu, S. Ranade, D. Ruthman, N. Watson, T. Ortmeyer, J. Wikston, A. Medina, A. Testa, R. Gardinier, V. Dinavahi, F. Acram, and P. Lehn, "Modeling devices with nonlinear voltage-current characteristics for harmonic studies," IEEE Trans. Power Del., vol. 19, no. 4, pp. 1802-1811, Oct. 2004.

[19] A. Damnjanovic and G. Feruson, "The measurement and evaluation of distribution transformer losses under nonlinear loading," in Proc. Power Eng. Soc. General Meeting, Jun. 2004, pp. 1416-1419.

[20] M. B. B. Sharifian, J. Faiz, S. A. Fakheri, and A. Zraatparvar, "Derating of distribution transformers for non-sinusoidal load currents using finite element method," in Proc. 10th IEEE Int. Conf. Electronics, Circuits and Systems, Dec. 2003, vol. 2, pp. 754-757.

[21] A. W. Kelley, S. W. Edwards, J. P. Rhode, and M. E. Baran, "Transformer derating for harmonic currents: A wide-band measurement approach for energized transformers," IEEE Trans. Ind. Appl., vol. 35, no. 6, pp. 1450-1457, Nov./Dec. 1999.

[22] E. F. Fuchs, D. Yildirim, and T. Batan, "Innovative procedure for measurement of losses of transformers supplying nonsinusoidal loads," Proc. Inst. Elect. Eng., vol. 146, pp. 617-625, 1999.

[23] M. T. Bishop, J. F. Baranowski, D. Heath, and S. J. Benna, "Evaluating harmonic-induced transformer heating," IEEE Trans. Power Del., vol. 11, no. 1, pp. 305-311, Jan. 1996.

[24] M. T. Bishop and C. Gilker, "Portable harmonics meter evaluates transformer heating," IEEE Comput. Appl. Power, vol. 5, pp. 41-44, Oct. 1992.

[25] D. E. Rice, "Adjustable speed drive and power rectifier harmonics-their effect on power system components," IEEE Trans. Ind. Appl., vol. 22, no. 1, pp. 161-177, Jan./Feb. 1986.

[26] N. Mohan, T. M. Undeland, and W. P. Robbins, Power Electronics: Converters, Applications, and Design, 3rd ed. Hoboken, NJ: Wiley, 2003.

[27] E. F. Fuchs and M. A. S. Masoum, Power Quality of Electric Machines and Power Systems. New York: Academic, 2008. 
Mohammad A. S. Masoum (SM'05) received the B.S., M.S., and Ph.D. degrees in electrical and computer engineering from the University of Colorado at Boulder in 1983, 1985, and 1991, respectively.

His research interests include optimization, power quality and stability of power systems/electric machines, and distributed generation. Currently, he is an Associate Professor with the Electrical and Computer Engineering Department, Curtin University of Technology, Perth, Australia.

Paul S. Moses received the B.Eng. and B.Sc. degrees in electrical engineering and physics in 2006 from Curtin University of Technology, Perth, Australia.

His interests include power system quality, protection schemes, and power electronics. Currently, he is a Systems Engineer at the Defence Science and Technology Organisation, Department of Defence, WA, Australia.
Amir S. Masoum (S'06) is currently pursuing the B.Sc. degree in electrical engineering at the University of Western Australia, Crawley, WA, Australia.

He is also with Magellan Power, Bibra Lake, Perth, WA, Australia. His main interests are power electronics and communication systems. 